Article

\title{
Docking and Antiherpetic Activity of 2-Aminobenzo[de]-isoquinoline-1,3-diones
}

\author{
Rashad Al-Salahi ${ }^{1}$, Ibrahim Alswaidan ${ }^{1}$, Hazem A. Ghabbour ${ }^{1}$, Essam Ezzeldin ${ }^{2}$, \\ Mahmoud Elaasser ${ }^{3}$ and Mohamed Marzouk ${ }^{1,4, *}$
}

1 Department of Pharmaceutical Chemistry, College of Pharmacy, King Saud University, P.O. Box 2457, Riyadh 11451, Saudi Arabia; E-Mails: salahi76@yahoo.com (R.A.-S.); ialsuwidan@ksu.edu.sa (I.A.); ghabbourh@yahoo.com (H.A.G.)

2 Drug Bioavailability Lab., College of Pharmacy, King Saud University, P.O. Box 2457, Riyadh 11451, Saudi Arabia; E-Mail: ezzeldin24@hotmail.com

3 Regional Center for Mycology and Biotechnology, Al-Azhar University, Naser City, Cairo 11759, Egypt; E-Mail: mmelaasser@hotmail.com

4 Chemistry of Natural Products Group, Center of Excellence for Advanced Sciences, National Research Center, Dokki, Cairo 12622, Egypt

* Author to whom correspondence should be addressed; E-Mail: mohmarzouk@ksu.edu.sa; Tel.: +966-11-467-7269; Fax: +966-11-467-6220.

Academic Editor: Derek J. McPhee

Received: 27 January 2015 / Accepted: 9 March 2015 / Published: 19 March 2015

\begin{abstract}
As part of our search for new compounds having antiviral effects, the prepared 2-aminonaphthalimide series was examined for its activity against the herpes simplex viruses HSV-1 and HSV-2. This represents the first study of the antiviral effects of this class of compounds. The new series of 2-amino- $1 H$-benzo[de]isoquinoline-1,3-diones was examined against HSV-1 and HSV-2 using a cytopathic effect inhibition assay. In terms of effective concentration (EC50), furaldehyde, thiophene aldehyde and allyl isothiocyanide derivatives 14-16 showed potent activity against HSV-1 $\left(\mathrm{EC}_{50}=19.6,16.2\right.$ and $17.8 \mu \mathrm{g} / \mathrm{mL})$, compared to acyclovir as a reference drug $\left(\mathrm{EC}_{50}=1.8 \mu \mathrm{g} / \mathrm{mL}\right)$. Moreover, 14 and 15 were found to exhibit valuable activity against HSV-2. Many of the tested compounds demonstrated weak to moderate $\mathrm{EC}_{50}$ values relative to their inactive parent compound (2-amino- $1 H$-benzo[de]isoquinoline-1,3-dione), while compounds 7, 9, 13, 14, 15, 16, 21 and 22 were the most active set of antiviral compounds throughout this study. The cytotoxicity $\left(\mathrm{CC}_{50}\right), \mathrm{EC}_{50}$, and the selectivity index (SI) values were determined. In a
\end{abstract}


molecular docking study, the ligand-receptor interactions of compounds 1-24 and their parent with the HSV-1 thymidine kinase active site were investigated using the Molegro Virtual Docker (MVD) software. Based on the potent anti-HSV properties of the previous naphthalimide condensate products, further exploration of this series of 2-amino- $1 \mathrm{H}$ benzo[de]isoquinoline-1,3-diones is warranted.

Keywords: 2-aminobenzo[de]isoquinoline-1,3-dione; docking; HSV-1; HSV-2

\section{Introduction}

HSV-1 and HSV-2, as DNA viruses, belong to the alpha herpes virus subfamily, which also includes the varicella zoster virus (VZV). They are common human pathogens and between 60\% and 95\% of certain populations are infected with HSV-1, and between $6 \%$ and $50 \%$ with HSV-2 [1,2]. Herpes simplex viruses are common pathogens that also cause herpes genitalis, herpes labialis, encephalitis and keratitis. The infection caused by the two types is mainly transmitted by close personal contact, and the virus establishes lifelong latent infection in the sensory neurons, with recurrent lesions $[3,4]$. The frequency of HSV-seropositive males is significantly higher in populations infected with the human immunodeficiency virus (HIV). Moreover, sexually transmitted diseases like genital HSV increase the risk of transmission and acquisition of HIV infection [5]; there is also a synergistic relationship between genital herpes and HIV [6]. It was reported that HSV-suppressive therapy greatly reduced genital and plasma levels in patients co-infected by HIV-1 RNA [7]. Hence, reducing the spread of genital herpes can greatly decrease the risk of acquiring or transmitting HIV infection.

Imides of aromatic dicarboxylic acids like naphthalimides are important in the construction of macromolecules as well as in supramolecular assembly. They are useful fluoroprobes for various studies and also serve as precursors for the protection of the amino group [8]. The $1 H$-benzo[de]isoquinoline-1,3-diones are also found to play an important role as synthons for the construction of many bioactive compounds such as antitumour and histone deacetylase inhibitors (HDAC) [9-16]. Moreover, they have a high binding affinity towards the 5-HT $1 \mathrm{~A}$ receptor that is expressed in Chinese hamster ovary cells (CHO cells, commonly used in biological, medical research and the most mammalian hosts for industrial production of recombinant protein therapeutics), as determined by fluorescence microscopy [17]. In our recent research, the title compounds were evaluated for their antimicrobial and cytotoxic effects, whereby some of them were found to possess significant activities $[18,19]$. Despite promising findings in the literature, most such compounds have been poorly studied because of their complicated syntheses [11]. In view of these facts, we aimed to investigate a new prepared series of 2-aminobenzo[de]isoquinoline-1,3-diones as antiviral agents against HSV-1 and HSV-2. 


\section{Results and Discussion}

\subsection{Antiviral Activity}

In our previous research, we have described the synthetic routes and full characterisation of compounds 1-24, as illustrated in Scheme 1 and Table 1 [20].
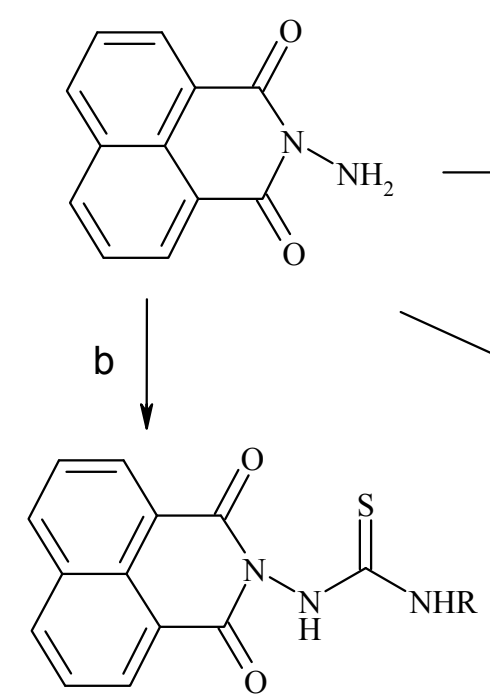

16-18

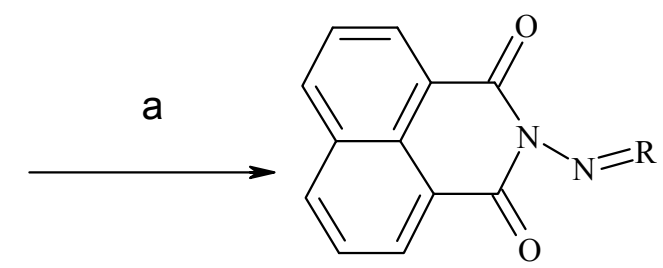

1-15

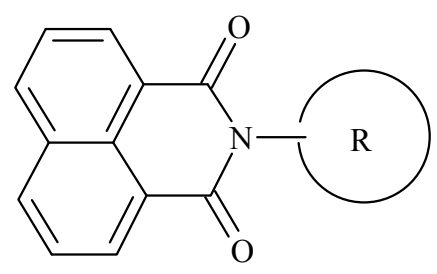

19-24

a: aldehydes, DMF, refluxing for $5.5 \mathrm{~h}$, b: isothiocyanides, DMF, refluxing for $6 \mathrm{~h}$, c: acid anhydrides, glacial acetic acid, refluxing for $6 \mathrm{~h}$.

Scheme 1. Main routes for synthesis of the target compounds 1-24.

Table 1. Synthesised 2-aminobenzo[de]isoquinoline-1,3-dione derivatives 1-24.

Cpd.


Table 1. Cont.

Cpd.

The present work reports our evaluation of the in vitro antiviral activity of the newly prepared 2-aminobenzo-[de]isoquinoline-1,3-diones against HSV-1 and HSV-2 by means of a cytopathic effect inhibition assay. From the obtained results, it can be seen that the target molecules possess weak to moderate anti-HSV activity. The in vitro results of the tested samples against both HSV-1 and HSV-2 are recorded in Table 2, where target compounds 14, 15 and 16 show remarkable and significant activity against $\mathrm{HSV}-1$, with $\mathrm{EC}_{50}$ values of $19.6,16.2$ and $17.8 \mu \mathrm{g} / \mathrm{mL}$, respectively, with respect to acyclovir $(1.8 \mu \mathrm{g} / \mathrm{mL})$ and their inactive parent compound (2-amino-1H-benzo[de]isoquinoline-1,3dione, Scheme 1). Furthermore, $\mathbf{1 4}$ and $\mathbf{1 5}$ also exhibited good activity against HSV-2, giving EC50 values of 71.8 and $56.7 \mu \mathrm{g} / \mathrm{mL}$, respectively, with respect to acyclovir (3.4 $\mu \mathrm{g} / \mathrm{mL})$. Compounds 7, 9, 21 and 22 displayed good activity against HSV-1 $\left(\mathrm{EC}_{50}=113.08,78.3,102\right.$ and $74.6 \mu \mathrm{g} / \mathrm{mL}$, respectively) in comparison with the previous active compounds. Additionally, compound 9 demonstrated good effect against HSV-2, relative to $\mathbf{1 4}$ and 15, with an EC50 value of $108 \mu \mathrm{g} / \mathrm{mL}$.

In terms of SI-values, all investigated compounds can be sorted into two groups: inactive $(\mathrm{SI}<2)$ and active (SI $\geq 2$ ) [21]. Accordingly, compounds 4, 5, 7, 9, 10, 13, 16, 17 and 21-23 can be considered as active agents. Compounds $\mathbf{1 4}$ and $\mathbf{1 5}$ were found to be the most active compounds against HSV-1, and similarly, 9, 14 and $\mathbf{1 5}$ could be accounted the only active compounds against HSV-2 (Table 2).

The present cytotoxicity evaluation of target products 1-24 revealed a variety in activity, in which compounds 14, 15 and 16 yielded the highest effects against HSV-1, while 7, 9, 21 and 22 manifested a good antiviral effect. On the other hand, 5, 6, 10, 17, 18 and 23 showed low activity against HSV-1, while 4, 7, 10, 13 and 21 showed low activity against HSV-2, in comparison with compounds 14-16. 
Table 2. Antiviral activity of compounds $\mathbf{1}-\mathbf{2 4}$ in terms of $\mathrm{CC}_{50}, \mathrm{EC}_{50}(\mu \mathrm{g} / \mathrm{mL})$ and $\mathrm{SI}$ against HSV-1 and HSV-2.

\begin{tabular}{cccccc}
\hline \multirow{2}{*}{ Cpd Nr. } & \multirow{2}{*}{$\mathbf{C C}_{\mathbf{5 0}}$} & \multicolumn{2}{c}{ HSV-1 } & \multicolumn{2}{c}{ HSV-2 } \\
\cline { 3 - 6 } & & $\mathbf{E C}_{\mathbf{5 0}}$ & $\mathbf{S I}$ & $\mathbf{E C}_{\mathbf{5 0}}$ & $\mathbf{S I}$ \\
\hline $\mathbf{1}$ & $375 \pm 25$ & $>500$ & - & $>500$ & - \\
$\mathbf{2}$ & $317 \pm 13$ & $>500$ & - & $>500$ & - \\
$\mathbf{3}$ & $196 \pm 22$ & $158 \pm 1.8$ & 1.2 & $>500$ & - \\
$\mathbf{4}$ & $486 \pm 18$ & $189 \pm 3.2$ & 2.6 & $312 \pm 9.6$ & 1.6 \\
$\mathbf{5}$ & $452 \pm 9$ & $176 \pm 4.6$ & 2.6 & $>500$ & - \\
$\mathbf{6}$ & $316 \pm 11$ & $174 \pm 1.8$ & 1.8 & $>500$ & - \\
$\mathbf{7}$ & $412 \pm 24$ & $113 \pm 4.6$ & 3.6 & $220 \pm 3.8$ & 1.9 \\
$\mathbf{8}$ & $289 \pm 13$ & $>500$ & - & $>500$ & - \\
$\mathbf{9}$ & $236 \pm 8$ & $78.3 \pm 1.5$ & 3.0 & $108 \pm 4.1$ & 2.2 \\
$\mathbf{1 0}$ & $380 \pm 16$ & $149 \pm 5.3$ & 2.6 & $416 \pm 8.2$ & 0.9 \\
$\mathbf{1 1}$ & $316 \pm 24$ & $>500$ & - & $>500$ & - \\
$\mathbf{1 2}$ & $320 \pm 18$ & $>500$ & - & $>500$ & - \\
$\mathbf{1 3}$ & $458 \pm 27$ & $117.2 \pm 3.1$ & 3.9 & $308 \pm 7.1$ & 1.5 \\
$\mathbf{1 4}$ & $321 \pm 23$ & $19.6 \pm 0.9$ & 16.4 & $71.8 \pm 1.8$ & 4.5 \\
$\mathbf{1 5}$ & $180 \pm 8$ & $16.2 \pm 1.1$ & 11.1 & $56.7 \pm 2.6$ & 3.2 \\
$\mathbf{1 6}$ & $96 \pm 12$ & $17.8 \pm 1.4$ & 5.4 & $292 \pm 4.8$ & 0.3 \\
$\mathbf{1 7}$ & $518 \pm 34$ & $236 \pm 4.9$ & 2.2 & $>500$ & - \\
$\mathbf{1 8}$ & $482 \pm 14$ & $319 \pm 3.7$ & 1.5 & $>500$ & - \\
$\mathbf{1 9}$ & $220 \pm 16$ & $>500$ & - & $>500$ & - \\
$\mathbf{2 0}$ & $220 \pm 16$ & $>500$ & - & $>500$ & - \\
$\mathbf{2 1}$ & $490 \pm 21$ & $102 \pm 5.8$ & 4.8 & $374 \pm 3.7$ & 1.3 \\
$\mathbf{2 2}$ & $560 \pm 46$ & $74.6 \pm 3.4$ & 7.5 & $428 \pm 10.2$ & 1.3 \\
$\mathbf{2 3}$ & $412 \pm 18$ & $176 \pm 2.4$ & 2.3 & $>500$ & - \\
$\mathbf{2 4}$ & $386 \pm 17$ & $>500$ & - & $>500$ & - \\
Parent & $320 \pm 24$ & $>500$ & - & $>500$ & - \\
\hline $\mathbf{c y c l o v i r}$ & $600 \pm 18$ & $1.8 \pm 0.2$ & 333.33 & $3.4 \pm 0.6$ & 176.47 \\
\hline
\end{tabular}

Notes: Cells treated with DMSO (0.1\%) were used as a negative control, and its reading was subtracted from the readings of tested compounds. Parent $=2$-amino- $1 H$-benzo[de $]$ isoquinoline-1,3-dione. Statistics were calculated using one-way ANOVA.

Regarding the elaborated results, biological studies have shown that the type of substituent produced from the condensation reaction with the amino group is a controlling factor governing all of the observed pharmacological properties in the parent structure. This is seen in the increment of antiviral activity in the sequence 15, 16 and 14 against HSV-1, whereas compound 15 showed higher activity than 14 against HSV-2. This could be attributed to the size and conformation of the heteroaldehyde and isothiocyanide substituents, which could have a substantial effect on the activity and selectivity profiles of such compounds. Throughout this study, we noticed that variation in the substituent on the benzyl ring resulted in a remarkable change in the activity profile. Regarding this fact, it was found that compounds $\mathbf{7}$ and $\mathbf{9}$ appeared as the most active among all aromatic aldehydes 3-7, 9 and 10 against HSV-1. In addition, compound 9 seemed to be most highly active against HSV-1 from the group of compounds that also includes 4, 7 and 10. Concerning the isothiocyanide 
derivatives, compound 16 was more active than 17 and 18 against HSV-1. Finally, the antiviral activity increased in the order of $\mathbf{2 2}>\mathbf{2 1}>\mathbf{2 3}$ against HSV-1 and $\mathbf{2 1}>\mathbf{2 2}$ against HSV-2 in the case of acid anhydride derivatives. In a comparison of $\mathrm{EC}_{50}$ with the corresponding $\mathrm{CC}_{50}$ values, compounds $\mathbf{1}, \mathbf{2}$, $\mathbf{8}, 11,12,19,20,24$ and the parent were inactive, whereby they showed higher $\mathrm{EC}_{50}$ than $\mathrm{CC}_{50}$ values (>500 $\mu \mathrm{g} / \mathrm{mL}$, Table 2). However, compounds 9, 14, 15, 16 and 22 were considered the most active compounds in comparison with others, but less active than acyclovir (Table 2).

The cytopathic effect inhibition assay showed that some of the examined compounds have good antiviral activity against HSV-1 and 2 in vitro at non-cytotoxic concentrations with respect to their $\mathrm{EC}_{50}$ and SI values, compared to acyclovir. In order to understand the temporal aspects of the antiviral activity of target molecules, it could be suggested that the possible mode of action of such compounds is not the prevention of viral adsorption or penetration, but perhaps an interference in early events of HSV replication, including immediate early (IE) transcriptional events [22,23]. The actual explanation for these changes regarding structure-activity relationship will await the elucidation of the mechanism(s) of action of the compounds.

\subsection{Molecular Docking}

Thymidine kinase (TK) acts catalytically to phosphorylate thymidine, getting it ready for further phosphorylation and eventual incorporation into DNA [24]. So many researches study the binding capabilities TK and other ligands can serve to develop more effective HSV treatment that would act as inhibitors of this enzyme rather than substrates.

In the present study, the ligand-receptor interactions of compounds 1-24 and the parent compound with HSV-1 thymidine kinase active site were investigated by performing docking studies using the Molegro Virtual Docker (MVD) software. The crystal structure of HSV-1 thymidine kinase in complex with acyclovir (PDB code 1KI5) was obtained from the Protein Data Bank [25] (Figure 1). The accuracy of MVD docking protocol was validated and confirmed by docking the co-crystallized acyclovir inside the active site of TK where the docked acyclovir showed little deviation (Figure 2).

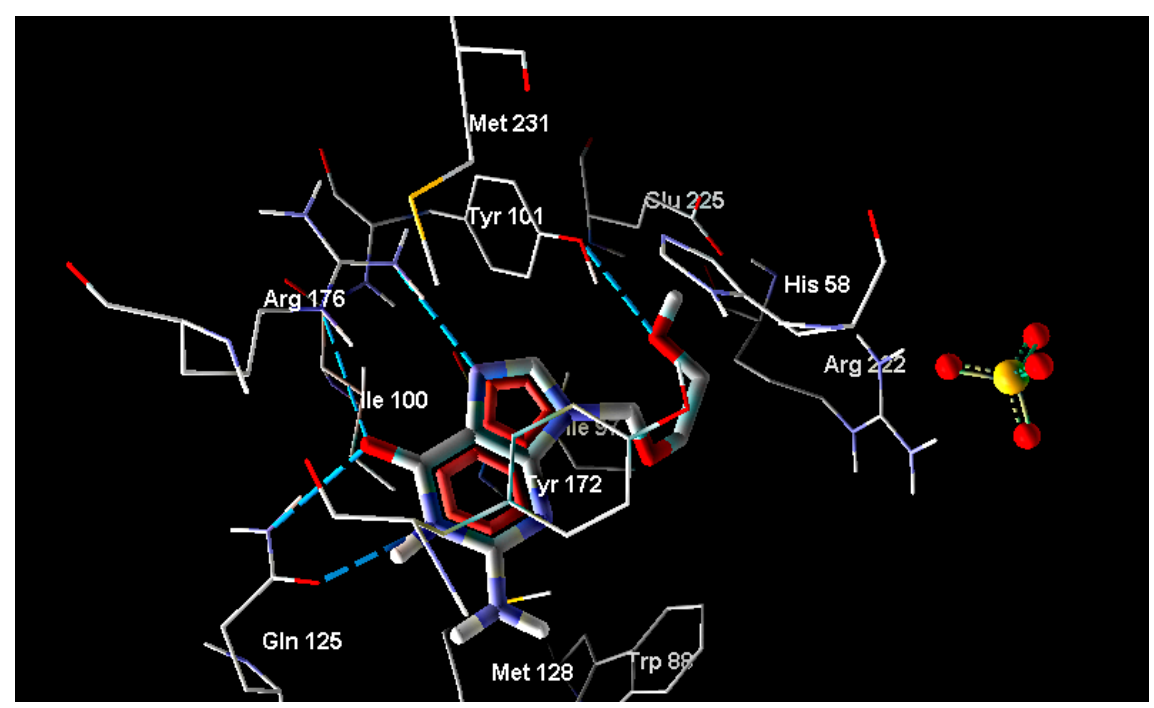

Figure 1. Interaction of acyclovir with thymidine kinase. 


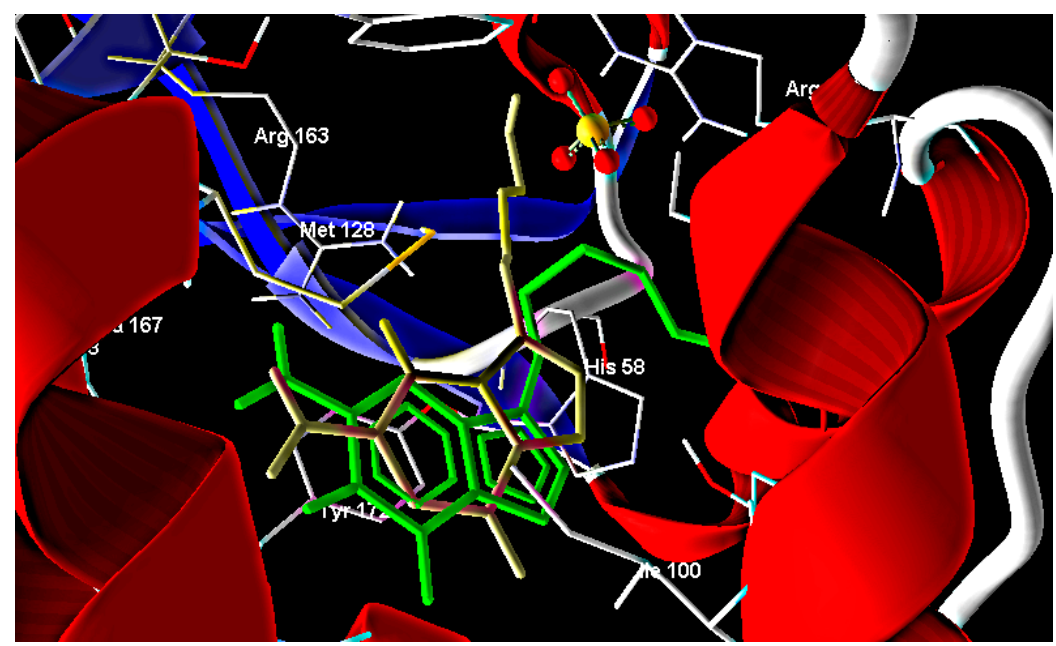

Figure 2. Comparison between the co-crystallized acyclovir (gray) and docked acyclovir (green).

Snapshots for the most active tested compounds were taken to reveal their molecular interactions (hydrogen, hydrophobic and/or ionic bonds) with the amino acids-HSV-1 thymidine kinase active sites. MolDock scores between these compounds and receptor were calculated (Table 3).

Table 3. MolDock scores of the acyclovir, parent and tested compounds 1-24.

\begin{tabular}{cccccc}
\hline Ligand & MolDock Score & Ligand & MolDock Score & Ligand & MolDock Score \\
\hline Parent & -101.205 & $\mathbf{9}$ & -112.001 & $\mathbf{1 8}$ & -134.765 \\
$\mathbf{1}$ & -97.8437 & $\mathbf{1 0}$ & -108.487 & $\mathbf{1 9}$ & -112.904 \\
$\mathbf{2}$ & -102.893 & $\mathbf{1 1}$ & -104.531 & $\mathbf{2 0}$ & -118.027 \\
$\mathbf{3}$ & -102.959 & $\mathbf{1 2}$ & -115.317 & $\mathbf{2 1}$ & -93.0316 \\
$\mathbf{4}$ & -95.8232 & $\mathbf{1 3}$ & -101.817 & $\mathbf{2 2}$ & -91.99 \\
$\mathbf{5}$ & -113.363 & $\mathbf{1 4}$ & -116.126 & $\mathbf{2 3}$ & -73.5124 \\
$\mathbf{6}$ & -127.137 & $\mathbf{1 5}$ & -112.552 & $\mathbf{2 4}$ & -133.133 \\
$\mathbf{7}$ & -109.968 & $\mathbf{1 6}$ & -129.001 & acyclovir & -111.737 \\
$\mathbf{8}$ & -121.392 & $\mathbf{1 7}$ & -132.879 & & \\
\hline
\end{tabular}

The results showed that all tested compounds have affinity for HSV-1 thymidine kinase comparable to that of the reference compound. The docking interaction of the most active compound $\mathbf{1 5}$ with the the active site of TK is represented in Figure 3. It is observed that the 2-amino group, carbonyl groups and the nitrogen atom of the benzoisoquinoline-1,3-dione moiety form five H-bond interactions with Glu63 and Tyr172, with bond lengths of 2.53, 3.27, 3.01, 3.38 and $3.31 \AA$, respectively. In addition, the hydrophobic interactions with Tyr172 alongside the phenyl ring with Tyr132 and Trp88 appear to constrain the molecule in close proximity with the amino acids forming the aforementioned hydrogen bonding [24-26]. 


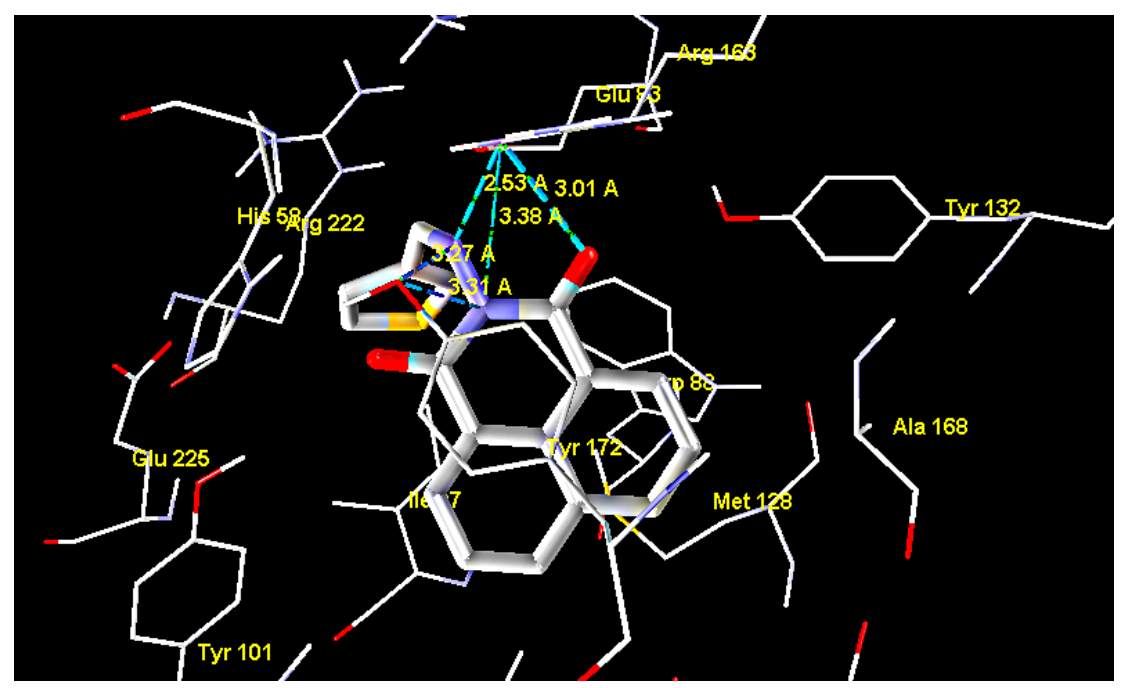

Figure 3. Interaction of compound 15 with thymidine kinase.

\section{Experimental Section}

\subsection{Mammalian Cell Line}

Vero cells (derived from the kidney of a normal African green monkey) were obtained from the American Type Culture Collection (ATCC, Manassas, VA, USA). The viral strains used were GHSV-UL46 for HSV-1 and the G strain for HSV-2. The Vero cells were propagated in Dulbecco's modified Eagle's medium (DMEM) supplemented with 10\% heat-inactivated foetal bovine serum (FBS), $1 \%$ L-glutamine, HEPES buffer and $50 \mu \mathrm{g} / \mathrm{mL}$ gentamycin. All cells were maintained at $37{ }^{\circ} \mathrm{C}$ in a humidified atmosphere with $5 \% \mathrm{CO}_{2}$ and were subcultured two times a week [19,27].

\subsection{Evaluation of the Antiviral Activity}

The antiviral screening was performed using a cytopathic effect inhibition assay at the Regional Center for Mycology and Biotechnology (RCMB, Al-Azhar University, Cairo, Egypt) [19,27]. This assay was selected to show specific inhibition of a biological function, that is, a cytopathic effect in susceptible mammalian cells [28]. In brief, monolayers of 10,000 Vero cells adhering at the bottom of the wells in a 96-well microtiter plate were incubated for $24 \mathrm{~h}$ at $37{ }^{\circ} \mathrm{C}$ in a humidified incubator with $5 \% \mathrm{CO}_{2}$. The plates were washed with fresh DMEM and challenged with $10^{4}$ doses of herpes simplex 1 or 2 virus, and then the cultures were simultaneously treated with two-fold serial dilutions of the tested compound, starting from $500 \mu \mathrm{g} / \mathrm{mL}$ and going up to about $2 \mu \mathrm{g} / \mathrm{mL}(500,250,125,62.5, \ldots$, $1.95 \mu \mathrm{g} / \mathrm{mL}$ ) in a fresh maintenance medium; following this, they were incubated at $37{ }^{\circ} \mathrm{C}$ for $48 \mathrm{~h}$. An infection control, as well as an untreated Vero cell control were made in the absence of tested compounds. Six wells were used for each concentration of the tested compound. Every $24 \mathrm{~h}$, an observation was made under the inverted microscope until the virus in the control wells showed complete viral-induced cytopathic effects. Antiviral activity was determined by the inhibition of the cytopathic effect compared to a control, that is, the protection offered by the tested compound to the cells was scored [29]. Three independent experiments were assessed, each containing four replicates 
per treatment. Acyclovir, which is clinically used for the treatment of herpetic viral disease, was used as positive control in this assay system [30].

After the incubation period, the media was aspirated, and then the cells were stained with a $1 \%$ crystal violet solution for $30 \mathrm{~min}$. Thereafter, all excess stain was removed by rinsing the plates with tap water. The plates were allowed to dry, and then glacial acetic acid (30\%) was added to all wells and mixed thoroughly. The absorbance of the plates was measured after gentle shaking on a microplate reader (Tecan Inc., Morrisville, NC, USA), at $590 \mathrm{~nm}$ [19,27]. The viral inhibition rate was calculated as follows:

$$
[(\text { ODtv }- \text { ODcv }) /(\text { ODcd }- \text { ODcv })] \times 100 \%
$$

where ODtv, ODcv and ODcd indicate the absorbance of the tested compounds with virus-infected cells, the absorbance of the virus control and the absorbance of the cell control, respectively.

From these data, the dose that inhibited viral infection by $50 \%$ (EC50) was estimated with respect to the virus control from the graphic plots, using the STATA modelling software. EC50 values were determined directly from the curve obtained by plotting the inhibition of the virus yield against the concentration of the samples. The selectivity index (SI) was calculated from the ratio of $\mathrm{CC}_{50}$ to $\mathrm{EC}_{50}$ in order to determine whether each compound had sufficient antiviral activity that exceeded its level of toxicity [31]. This index is referred to as a therapeutic index, and it was also used to determine whether a compound warranted further study. Compounds that had an SI-value of 2 or more were considered to be active $[19,27]$.

\subsection{Cytotoxicity Evaluation Using Viability Assay}

The Vero cell lines in the cytotoxicity assay were seeded in 96-well plates at a cell concentration of $1 \times 10^{4}$ cells per well in $100 \mu \mathrm{L}$ of the growth medium [29]. Fresh medium containing different concentrations of the tested sample was added after $24 \mathrm{~h}$ of seeding. Serial two-fold dilutions of the tested compound were added to confluent cell monolayers dispensed into 96-well, flat-bottomed microtiter plates (Falcon, Jersey, NJ, USA) using a multichannel pipette. The microtiter plates were incubated at $37{ }^{\circ} \mathrm{C}$ in a humidified incubator with $5 \% \mathrm{CO}_{2}$ for a period of $48 \mathrm{~h}$. Three wells were used for each concentration of the tested sample. Control cells were incubated without test samples and with or without DMSO. The small percentage of DMSO present in the wells (maximal 0.1\%) was not found to affect the experiment $[19,27]$.

After the end of the incubation period, the viable cell yield was determined by a colorimetric method [32-36]. In brief, the process of treatment the media with crystal violet solution and measurement of absorbance at $590 \mathrm{~nm}$ using a microplate reader was mentioned above. The absorbance was proportional to the number of surviving cells in the culture plate. All the results were corrected for background absorbance detected in wells without added stain. Treated samples were compared with the cell control in the absence of the tested compounds. All experiments were carried out in triplicate. The cell cytotoxicity effect of each tested compound was calculated [30,37]. 


\subsection{Molecular Docking}

Molecular docking studies were carried out on a laptop PC, Intel ${ }^{\circledR}$ Core TM i7-3630 QM CPU @ $2.40 \mathrm{GHz}, \mathrm{RAM} 8 \mathrm{~GB}$ operating under the Windows 7 Professional OS. It consists of several steps; first, the 3D crystal structures of HSV-1 thymidine kinase in complex with acyclovir (PDB code 1KI5) [25] was downloaded from the Brookhaven Protein Data Bank PDB and loaded into Molegro Virtual Docker (MVD 2013.6.0.0 [win32] program fully functional free trial version with time limiting license [38]. All types of atoms, charges and bond hybridization were carefully checked. The MolDock Score [GRID] and MolDock Optimizer routines as implemented in Molegro Virtual Docker (MVD version 2013.6.0.0). The non-bonded oxygen atoms of water molecules, present in the crystal structure, were removed. ChemBio3D Ultra 10 was used to draw the 3D structures of different ligands that were further pre-optimized using free version of Marvinsketch 4.1.13 from Chemaxon Ltd. with MM force field and saved in Tripos mol2 file format [39]. MolDock score functions were used with a $0.3 \AA$ grid resolution. Prior to the calculations of the examined compounds, the MVD software was benchmarked by docking the acyclovir.

\subsection{Data Analysis}

Statistics were done using a one-way ANOVA test [40], and the percentage cell viability was calculated using Microsoft Excel ${ }^{\circledR}$, as follows:

$$
\% \text { Cell viability }=[(\text { Mean Abscontrol }- \text { Mean Abstest metabolite }) / \text { Mean Abscontrol }] \times 100
$$

where Abs equals the absorbance at $590 \mathrm{~nm}$. The $\mathrm{CC}_{50}$ was estimated from graphic plots and the STATA statistical analysis package was used for the drawing of the dose response curve, in order to calculate $\mathrm{CC}_{50}$. Concerning antiviral evaluation, all experiments and data analysis were performed in RCMB, Al-Azhar University, Cairo, Egypt.

\section{Conclusions}

This study has revealed that compounds $\mathbf{1 4 , 1 5}$ and $\mathbf{1 6}$ are active agents against both herpes simplex viruses. These compounds could be useful as templates for furthering development and design of more potent antiviral agents.

\section{Acknowledgments}

The authors extend their appreciation to the Deanship of Scientific Research at King Saud University for funding this work through research group No RG-1435-068.

\section{Author Contributions}

Rashad Al-Salahi has made a substantial contribution to the experimental design, significant contributions to the acquisition of data, manuscript preparation (writing and revision) and approved the final form of the manuscript. Ibrahim Alswaidan has participated in the reading and revision processes and approved the final form of the manuscript. Essam Ezzeldin has written and analyzed the statistical data and participated in the revision process and approved the final form of the manuscript. 
Hazem A. Ghabbour has performed the molecular docking work. Mahmoud Elaasser has performed substantial biological investigation tests. Mohamed Marzouk has made a substantial contribution to the experimental design, significant contributions to the acquisition of data and manuscript preparation (writing and revision) and approved the final form of the manuscript.

\section{Conflicts of Interest}

The authors declare no conflict of interest.

\section{References}

1. Smith, J.S.; Robinson, J.N. Age-specific prevalence of infection with herpes simplex virus types 1 and 2: A global review. J. Infect. Dis. 2002, 186, S3-S28.

2. Akanitapichata, P.; Wangmaneerata, A.; Wilairatb, P.; Bastowc, K.F. Anti-herpes virus activity of Dunbari abella Prain. J. Ethnopharmacol. 2006, 105, 64-68.

3. Fatahzadeh, M.; Schwartz, R.A. Human herpes simplex virus infections: Epidemiology, pathogenesis, symptomatology, diagnosis, and management. J. Am. Acad. Dermatol. 2007, 57, 737-763.

4. Cowan, F.M.; French, R.S.; Mayaud, P.; Gopal, R.; Robinson, N.J.; de Oliveira, S.A.; Faillace, T.; Uusküla, A.; Nygård-Kibur, M.; Ramalingam, S.; et al. Seroepidemiological study of herpes simplex virus types 1 and 2 in Brazil, Estonia, India, Morocco, and Sri Lanka. Sex. Transm. Infect. 2003, 79, 286-290.

5. Safrin, S.; Crumpacker, C.; Chatis, P.; Davis, R.; Hafner, R.; Rush, J.; Kessler, H.A.; Landry, B.; Mills, J. A controlled trial comparing foscarnet with vidarabine for acyclovir-resistant muco cutaneous herpes simplex in the acquired immunodeficiency syndrome: The AIDS clinical trials group. N. Eng. J. Med. 1991, 325, 551-555.

6. White, M.K.; Gorrill, T.S.; Khalili, K. Reciprocal transactivation between HIV-1 and other human viruses. Virology 2006, 352, 1-13.

7. Wald, A. Synergistic interactions between herpes simplex virus type-2 and human immunodeficiency virus epidemics. Herpes 2004, 11, 70-76.

8. Barooah, N.; Tamuly, C.; Baruah, J.B. Synthesis, characterisation of few $N$-substituted 1,8-naphthalimide derivatives and their copper(II) complexes. J. Chem. Sci. 2005, 117, 117-122.

9. Xu, Y.; Qu, B.; Qian, X.; Li, Y. Five-member thio-heterocyclic fused naphthalimides with aminoalkyl side chains: Intercalation and photocleavage to DNA. Bioorg. Med. Chem. Lett. 2005, $15,1139-1142$.

10. Mukherjee, A.; Hazra, S.; Dutta, S.; Muthiah, S.; Mondhe, D.M.; Sharma, P.R.; Singh, S.K.; Saxena, A.K.; Qazi, G.N.; Sanyal, U. Antitumor efficacy and apoptotic activity of substituted chloroalkyl $1 H$-benzo[de]isoquinoline-1,3-diones: A new class of potential antineoplastic agents. Investg. New Drugs 2011, 29, 434-442.

11. Brana, M.F.; Castellano, J.M.; Moran, M.; Pérez de Vega, M.J.; Romerdahl, C.R.; Qian, X.D.; Bousquet, P.; Emling, F.; Schlick, E.; Keilhauer, G. Bis-naphthalimides: A new class of antitumor agents. Anti-Cancer Drug Des. 1993, 8, 257-268.

12. Aibin, W.; Jide, L.L.; Shaoxiong, Q.; Ping, M. Derivatives of 5-nitro-1H-benzo[de]isoquinoline1,3(2H)-dione: Design, synthesis, and biological activity. Monatsh. Chem. 2010, 141, 95-99. 
13. Mukherjee, A.; Dutta, S.; Shanmugavel, M.; Mondhe, D.M.; Sharma, P.R.; Singh, S.K.; Saxena, A.K.; Sanyal, U. 6-Nitro-2-(3 hydroxypropyl)-1H-benz[de]isoquinoline-1,3-dione, a potent antitumor agent, induces cell cycle arrest and apoptosis. J. Exp. Clin. Cancer Res. 2010, 29, $175-182$.

14. Qazi, G.N.; Saxena, A.K.; Muthiah, S.; Mondhe, D.M.; Sharma, P.R.; Singh, S.K.; Sanyal, U.; Mukherjee, A.; Hazra, S.; Dutta, S. Preparation of benzisoquinolinedione derivatives for us as antitumor agents. WO 2008084496 A1, 17 July 2008.

15. Cholody, W.M.; Kosakowska-Cholody, T.; Michejda, C.J. Preparation of 1,8-naphthalimidolinked imidazo[4,5,1-de]acridones as bis-intercalating antitumor agents. WO 2001066545 A2, 13 September 2001.

16. Vaisburg, A.; Bernstein, N.; Frechette, S.; Allan, M.; Abou-Khalil, E.; Leit, S.; Moradei, O.; Bouchain, G.; Wang, J.; Woo, S.H.; et al. (2-Aminophenyl)-amides of omega-substituted alkanoic acids as new histone deacetylase inhibitors. Bioorg. Med. Chem. Lett. 2004, 14, 283-287.

17. Lacivita, E.; Leopoldo, M.; Masotti, A.C.; Inglese, C.; Berardi, F.; Perrone, R.; Ganguly, S.; Jafurulla, M.; Chattopadhyay, A. Synthesis and characterization of environment-sensitive fluorescent ligands for human 5-HT1A receptors with 1-arylpiperazine structure. J. Med. Chem. 2009, 52, 7892-7896.

18. Al-Salahi, R.; Marzouk, M. Some 2-amino-benzo[de]isoquinolin-1,3-diones as antimicrobial agents. Asian J. Chem. 2014, 26, 8163-8165.

19. Al-Salahi, R.; Alswaidan, I.; Marzouk, M. Cytotoxicity evaluation for a new set of 2-aminobenzo[de]iso-quinolin-1,3-diones. Int. J. Mol. Sci. 2014, 15, 22483-22491.

20. Al-Salahi, R.; Marzouk, M. Synthesis of novel 2-aminobenzo[de]isoquinolin-1,3-dione derivatives. Asian J. Chem. 2014, 26, 2166-2172.

21. Garett, R.; Romanos, M.T.V.; Borges, R.M.; Santos, M.G.; Rocha, L.; da Silva, A.J.R. Antiherpetic activity of a flavonoid fraction from Ocotea notata leaves. Braz. J. Pharmacogn. 2012, 22, 306-313.

22. Bag, P.; Ojha, D.; Mukherjee, H.; Halder, U.C.; Mondal, S.; Chandra, N.S.; Nandi, S.; Sharon, A.; Sarkar, M.C.; Chakrabarti, S.; et al. An indole alkaloid from a tribal folklore inhibits immediate early event in HSV-2 infected cells with therapeutic efficacy in vaginally infected mice. PLoS One 2013, 8, e77937.

23. Liang, Y.; Vogel, J.L.; Narayanan, A.; Peng, H.; Kristie, T.M. Inhibition of the histone demethylase LSD1 blocks $\alpha$-herpesvirus lytic replication and reactivation from latency. Nat. Med. 2009, 15, 1312-1317.

24. Champness, J.N.; Bennett, M.S.; Wien, F.; Viss, R.; Summers, W.C.; Herdewijn, P.; Ostrowski, E.; Jarvest, R.L.; Sanderson, M.R. Exploring the active site of herpes simplex virus type-1 thymidine kinase by X-ray crystallography of complexes with Aciclovir and other ligands. Proteins Struct. Funct. Genet. 1998, 32, 350-361.

25. Bennett, M.S.; Wien, F.; Champness, J.N.; Batuwangala, T.; Rutherford, T.; Summers, W.C.; Sun, H.; Wright, G.; Sanderson, M.R. Structure to $1.9 \AA$ resolution of a complex with herpes simplex virus type-1 thymidine kinase of a novel, non-substrate inhibitor: X-ray crystallographic comparison with binding of acyclovir. FEBS Lett. 1999, 443, 121-125. 
26. Luyten, I.; de Winter, H.; Busson, R.; Lescrinier, T.; Creuven, I.; Durant, F.; Baizarini, J.; de Clercq, E.; Herdwijn, P. Synthesis of 2'-deoxy-5-(isothiazol-5-yl)uridine and its interaction with the HSV-1 thymidine kinase. Helv. Chim. Acta 1996, 79, 1462-1474.

27. Al-Salahi, R.; Marzouk, M.; Alswaidan, I.; Al-Omar, M. Antiviral activity of 2-phenoxy-4H[1,2,4]triazolo[1,5-a]quinazoline derivatives. Life Sci. J. 2013, 10, 2164-2169.

28. Hu, J.M.; Hsiung, G.D. Evaluation of new antiviral agents I: In vitro prospective. Antivir. Res. 1989, 11, 217-232.

29. Vijayan, P.; Raghu, C.; Ashok, G.; Dhanaraj, S.A.; Suresh, B. Antiviral activity of medicinal plants of Nilgiris. Indian J. Med. Res. 2004, 120, 24-29.

30. Dargan, D.J. Investigation of the anti-HSV activity of candidate antiviral agents. In Methods in Molecular Medicine, Herpes Simplex Virus Protocols; Brown, S.M., MacLean, A.R., Eds.; Humana Press Inc.: Totowa, NJ, USA, 1998; Volume 10, pp. 387-405.

31. Zandi, K.; Zadeh, M.A.; Sartavi, K.; Rastian, Z. Antiviral activity of Aloe vera against herpes simplex virus type 2: An in vitro study. Afr. J. Biotechnol. 2007, 6, 1770-1773.

32. Vega-Avila1, E.; Pugsley, M.K. An overview of colorimetric assay methods used to assesssurvival or proliferation of mammalian cells. Proc. West. Pharmacol. Soc. 2011, 54, 10-14.

33. Bajbouj, K.; Schulze-Luehrmann, J.; Diermeier, S.; Amin, A.; Schneider-Stock, R. The anticancer effect of saffron in two p53 isogenic colorectal cancer cell lines. BMC Complement. Altern. Med. 2012, 12, 69.

34. Ušaj, M.; Trontelj, K.; Hudej, R.; Kandušer, M.; Miklavčič, D. Cell size dynamics and viability of cells exposed to hypotonic treatment and electroporation for electrofusion optimization. Radiol. Oncol. 2009, 43, 108-119.

35. Bernhardt, G.; Reile, H.; Birnboeck, H.; Spruss, T.; Schoenenberger, H. Standardized kinetic microassay to quantify differential chemosensitivity on the basis of proliferative activity. $J$. Cancer Res. Clin. Oncol. 1992, 118, 35-43.

36. Ait Mbarek, L.; ait Mouse, H.; Elabbadi, N.; Bensalah, M.; Gamouh, A.; Aboufatima, R.; Benharref, A.; Chait, A.; Kamal, M.; Dalal, A.; et al. Anti-tumor properties of blackseed (Nigella sativa L.) extracts. Braz. J. Med. Biol. Res. 2007, 40, 839-847.

37. Mosmann, T. Rapid colorimetric assay for cellular growth and survival: Application to proliferation and cytotoxicity assays. J. Immunol. Methods 1983, 65, 55-63.

38. Thomsen, R.; Christensen, M.H. MolDock: A new technique for high-accuracy molecular docking. J. Med. Chem. 2006, 49, 3315-3321.

39. Kerwin, S.M. ChemBioOffice Ultra 2010 suite. J. Am. Chem. Soc. 2010, 132, 2466-2467.

40. Castilla-Serna, L.; Cravioto, J. Simply Statistic for Health Investigation, 1st ed.; Trillas: Mexico, Mixico, 1999.

Sample Availability: Samples of the compounds (1-24) are available from the authors.

(C) 2015 by the authors; licensee MDPI, Basel, Switzerland. This article is an open access article distributed under the terms and conditions of the Creative Commons Attribution license (http://creativecommons.org/licenses/by/4.0/). 